\title{
Assessment of the Results of the Implementation of Strategic Network Management
}

\author{
Maksim Kocheryan*, Andrey Plakhin, Irina Vashlyaeva, Stanislava Fagina \\ Ural State University of Economics, Ekaterinburg, Russia \\ *Corresponding author.Email: mkocheryan@mail.ru
}

\begin{abstract}
The article is devoted to the assessment of the effects of the introduction of strategic network management on the example of physical culture and sports activities of universities in the Sverdlovsk region. The article provides an overview of theoretical approaches to assessing the effects of the introduction of strategic network management, based on which the research methodology is formed. This technique is based on a set of indicators characterizing social effects an increase in the number of people involved in physical culture and sports activities. The results of the study confirmed the author's hypothesis that the introduction of strategic network management increases the social efficiency of the existing resource base of physical culture and sports activities of universities in the Sverdlovsk region.
\end{abstract}

Keywords: network management, social efficiency, physical culture, and sports activities.

\section{INTRODUCTION}

Analyzing the works of Russian and foreign authors, we can single out several approaches to assessing the results of using the network methodology in the strategic management of a wide range of objects. In his article, Aarikka-Stenroos L. [1] notes that a new look at the content of the strategy, which was developed within the framework of the network approach, has changed the attitude towards the problem of managing the company's performance. In the network approach, the effectiveness of an organization is determined not by the level of its "adaptation" to the external environment, but by the achievement of compatibility with the market "context", which is formed through interaction and development of relationships with other actors. Summarizing the work of domestic and foreign researchers, we can highlight the value, process and resource approaches to assessing the effects of the introduction of strategic network management.

In the context of the value approach, an assessment of strategic network management is proposed from the standpoint of satisfying the needs of the subjects participating in network relationships, however, the issues of the compliance of this activity with the stages of strategy development are left without attention and there is no necessary toolkit for resource support for the implementation of the strategy.
The process methodological approach to assessing the results of the implementation of strategic network management presupposes that the development of a strategy must correspond to the stages of its formation and implementation, for example, the use of the wellknown method of SWOT-analysis is envisaged. Thus, in the article by Yu. D. Yakubov [2], the need to use an assessment of the effectiveness of strategic management through a seven-point assessment, corresponding to the use of a seven-stage procedure for forming a strategy, is noted.

So, from the standpoint of management, the use of strategic network management allows to achieve the following results:

- to structure the network of independent entities, first, due to the possibility of assessing their potential by using complexes of indicators.

- to stabilize the roles (organizational, coordinating, supporting) of network actors, securing them in the relevant contracts.

- to make a comprehensive assessment of the effectiveness and efficiency of activities with the subsequent optimization of network relations.

Thanks to the introduction of the provisions of strategic network management, it becomes possible to systematize individual subjects and structure the network they form by using various kinds of indicators and the 
corresponding prioritization of interactions within which these subjects enter network relations.

The advantages of using strategic network management can also consist in ensuring the stabilization of the roles (organizational, coordinating, supporting) of network actors by correlating them with individual functions. As noted above, another result from the implementation of the provisions of strategic network management can be the use of a developed methodological base for a comprehensive assessment of the effectiveness and efficiency of network interactions, based on which there is a reasonable possibility of carrying out a set of optimization procedures.

Evaluation of network relationships is carried out on the one hand to determine the optimal forms of interaction, and on the other for timely adjustment of the chosen form of interaction [3]. The choice of the form of network interaction is made when forming the company's portfolio strategy.

Thus, the use of the process approach in the methodological support of the analysis of the effectiveness of strategic network management makes it possible to streamline the individual stages of developing a strategy for network interaction, however, there are no ready-made algorithms in the base of scientific works now.

According to several authors, in the process of strategic network management, it is also necessary to assess the economic and resource efficiency. It is proposed to assess the effectiveness from the standpoint of reducing transaction costs in the article by D.S. Mironov [4]. Various network effects formed during partnerships are represented by Yu.F. Popova [5], these include reducing costs when coordinating the activities of partners, increasing margin income when introducing innovations.

We agree with the opinion of individual researchers about the importance of determining the effectiveness of strategic network management from the standpoint of social indicators The works provide such evaluation parameters as the degree of provision of sociodemographic groups of the population with various types of infrastructure for physical culture and sports,

Summing up the results of the study of the theoretical provisions of strategic network management, it should be noted that these provisions are substantiated within the framework of the theories of strategic and general management. From the standpoint of the theory of general management, strategic network management is a consistent implementation of management functions in relation to the design of network parameters: planning, organization, motivation, control, and coordination. It can also be stated that the use of a network strategy makes it possible to find a compromise between a unitary concept that limits activity to the resources of a specific subject and a stakeholder concept.

\section{METHODS}

The methodology presented in Figure 1 for multifactorial assessment of the strategic network management of physical culture and sports activities of a university, combines the above theoretical provisions, but at the same time allows to detail the value and resource indicators of physical culture and sports activities of a university in the context of individual events, which significantly increases the controllability and effectiveness of strategic network management, improves the efficiency of making management decisions and forms the basis for subsequent iterations of strategic planning by selecting appropriate measures for implementation.

The first stage of the proposed methodology provides for the allocation of individual events of physical culture and sports activity and the determination of the type of network interaction based on the following options:

- networking within the educational programs of the university.

- networking within the framework of the implementation of physical culture and sports events held by state and municipal authorities, enterprises, and public organizations.

The typology of network interactions allows to designate the priority of the educational activities of the university over the implementation of sports events held by state and municipal authorities, enterprises, and public organizations.

The second stage of the methodology includes a sequential description of the selected activities in a fourphase section. First, it is necessary to provide indicators describing the needs of the implementation of basic professional educational programs (BPEP) implemented by the university; for this, as the criterion the number of classroom hours of work can be used.

The detailing of the process of forming the necessary competencies should be carried out in accordance with the programs of disciplines that provide the formation of competencies as a result of the implementation of physical culture and sports activities of the university, which the majority of researchers, in particular I.V. Manzheley, S.N. Chernyakova [6], P.P. Ryskin [7], Plakhin A.E. [8] and a number of other researchers define as the required readiness of an individual for the implementation of various kinds of physical culture and sports activities. Competencies in the field of physical culture and sports are closely related to bodily and motor practices that contribute to the self-realization of the individual, the definition of priorities in the field of physical culture and sports. 
Stage 1 - Assignment and determination of the type of network interaction (NI) in the framework of physical culture and sports activity (PCSA) of the university

\begin{tabular}{c}
$\begin{array}{c}\text { Networking } \\
\text { within the } \\
\text { educational } \\
\text { programs of the } \\
\text { university }\end{array}$ \\
$\begin{array}{c}\text { Networking in the framework of the } \\
\text { implementation of physical culture and } \\
\text { sports events held by state and } \\
\text { municipal authorities, enterprises and } \\
\text { public organizations }\end{array}$ \\
\hline $\begin{array}{l}\text { Needs of implementation of basic professional } \\
\text { educational programs } \\
\text { Stage 2 - Formalization of key parameters for formed }\end{array}$ \\
\hline $\begin{array}{l}\text { Material, technical and financial } \\
\text { resources }\end{array}$ \\
\hline $\begin{array}{l}\text { Human resources of the event } \\
\text { imple event }\end{array}$ \\
\hline Sentation of network management
\end{tabular}

Figure 1 Methodology for multifactorial assessment of strategic network management of physical culture and sports activities of a university.

Formalizing the block for assessing the physical culture and sports activity of the university, dedicated to the implementation of the main professional educational programs, one cannot ignore the indicators of the official monitoring of the activities of universities. So, a number of target indicators of physical culture and sports activity are already included in the official monitoring of the activities of educational institutions of higher education of the Russian Federation, and, therefore, these indicators should be included in the description of the projects of physical culture and sports activity, among them:

1) the number of students professionally engaged in various types of sports activities.

2) the number of students involved in sports sections.

3 ) the number of physical culture and sports events at the university.

4) the quantitative results of information activities covering the sphere of physical culture and sports of the university.

The second group of indicators characterizing the physical culture and sports activity of the university should be the assessment of its social effects.
First, the physical culture and sports activity of the university should be characterized from the point of view of the value perception of this activity both by students and staff of the university, and by external stakeholders.

Secondly, the social effects of physical culture and sports activities correspond to the directions of development of physical culture enshrined in the strategies of the federal and regional levels. This approach makes it possible to coordinate the activities of higher education organizations, state and municipal authorities and obtain additional synergetic effects. The assessment of this effect is made by determining the growth of students' involvement in physical culture and sports events.

As indicators of the development of physical culture and sports, researchers offer a fairly large range of criteria that can be used in the proposed methodology for assessing the physical culture and sports activity of universities in several areas. In the work of A.M. Starostenko and K.V. Starostenko [9] it is said that the criteria for assessing the effective work of regional government bodies in the development of physical culture and sports, among other things, are the effectiveness of the local strategy for the development of physical culture and sports institutions that meet the interests and needs of all groups of the population and aimed at the implementation of federal and regional target programs and fixing the trends and dynamics of changes in the leisure time of young people, the level of their involvement in activities for the development of children and youth sports in the region, especially in secondary schools and other educational institutions.

Thus, the block of social effects in the implementation of measures of physical culture and sports activity of the university should include indicators reflecting a quantitative assessment of the involvement of the population in physical culture and sports with the allocation of a subgroup of young people.

Thirdly, each dedicated network interaction in the physical culture and sports activities of the university should be characterized by indicators of personnel and material and technical security. For example, it is noted that physical culture and sports activities should be analysed in the context of the following factors:

- the material and technical base of the physical culture and sports complex;

- personnel, financial and information security;

- the level of involvement, interests and needs of students

\section{RESULTS}

Figure 2 shows the results of modeling changes in the intensity of network interaction during the 


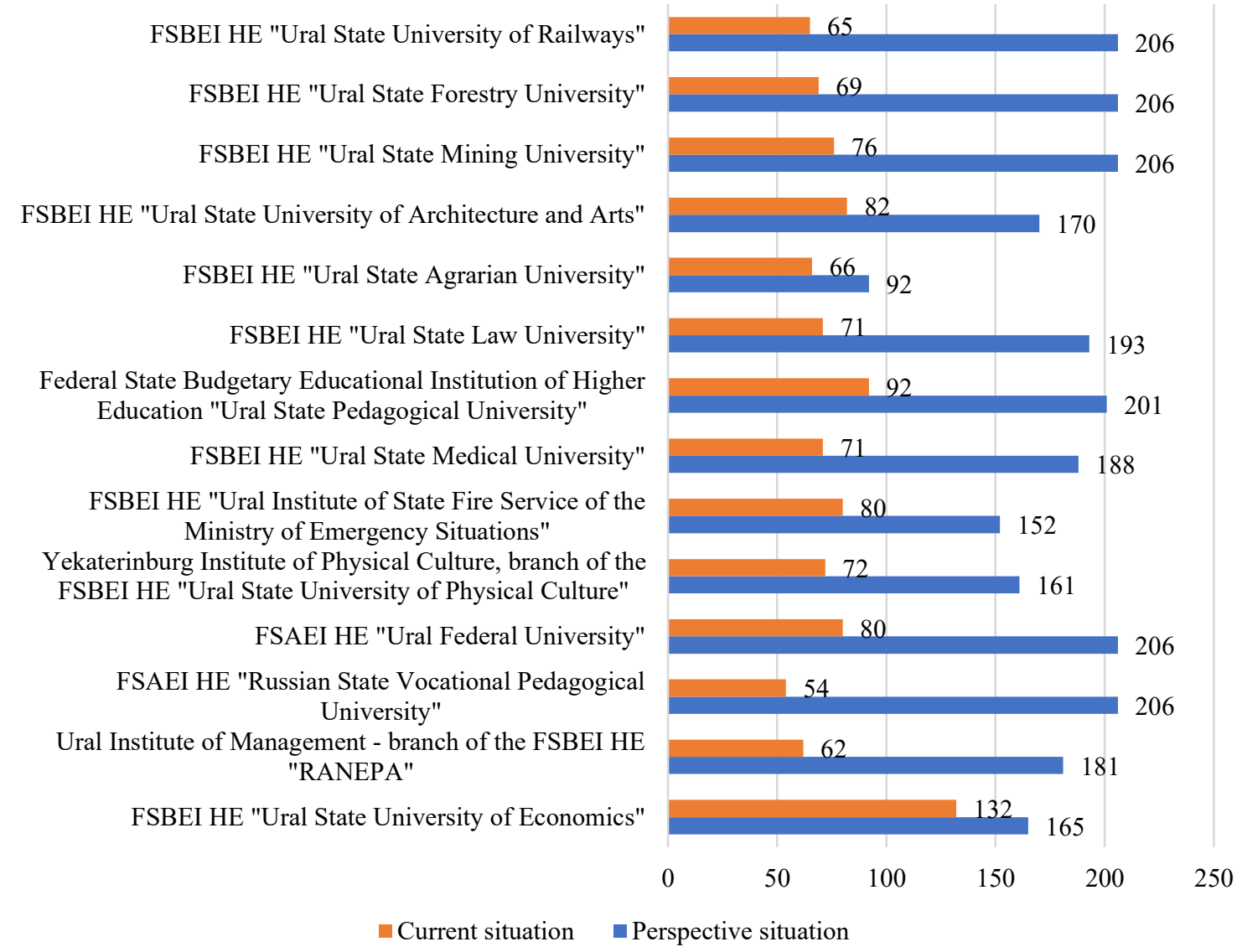

Figure 2 Change in the intensity of network interaction during the implementation of strategic network management of physical culture and sports activities of universities in the Sverdlovsk region.

implementation of strategic network management of physical culture and sports activities of universities in the Sverdlovsk region. As the simulation results show, the total number of network interactions can grow from 1,072 to 2,411 per year, or 2.3 times. Such intensity leads to an increase in participants in physical culture and sports activity from 55458 to 64193 people and, consequently, to a more efficient use of existing resources. Further, in Table 2, we present complex analytical information on the prospective transformation of strategic network interaction in the framework of the implementation of physical culture and sports activities of universities in the Sverdlovsk region, which allows to significantly expand the network interaction of universities to increase social efficiency while optimizing the use of resources of participants in the strategic network.

The analysis of the results of modeling the situation change presented in Table 2 shows that the implementation of the project approach using the developed methodological toolkit, consisting of the "Methods of multifactorial assessment of the strategic network management of the physical culture and sports activities of the university" and the "Conceptual model of the strategic network management of the physical culture and sports activities of the university" can to ensure an increase in coverage and an increase in the number of stable connections of participants in the network model.

The network model can be transformed from a concentric type to a distributed one by increasing the number of projects with more active participation of universities. As a result, links appear in the scheme of strategic network interaction due to the need to ensure the implementation of training courses, for the Ural State University of Economics, such links appear to overcome resource constraints.

In addition, network participants are much more actively involved in physical culture and sports events initiated by state and municipal authorities, as well as by the corporate sector, sports organizations, and universities proper. As the prospective modeling of strategic network interaction shows, the number of participants actively using the network strategy can grow.

\section{CONCLUSIONS}

The introduction of strategic network management of the physical culture and sports activities of the university 
Table 2. Summary data on the transformation of network interaction in the framework of physical culture and sports activities of universities.

\begin{tabular}{|c|c|c|c|c|c|c|}
\hline \multirow{2}{*}{ University } & \multicolumn{2}{|c|}{$\begin{array}{l}\text { Current situation according to } \\
\text { data for the 2019-2020 } \\
\text { academic year }\end{array}$} & \multicolumn{2}{|c|}{ Perspective situation } & \multicolumn{2}{|l|}{ Change } \\
\hline & $\begin{array}{l}\text { Network } \\
\text { coverage, \% }\end{array}$ & $\begin{array}{l}\text { Number of } \\
\text { stable links }\end{array}$ & $\begin{array}{l}\text { Network } \\
\text { coverage, \% }\end{array}$ & $\begin{array}{l}\text { Number of } \\
\text { stable } \\
\text { links }\end{array}$ & $\begin{array}{l}\text { Network } \\
\text { coverage, } \%\end{array}$ & $\begin{array}{l}\text { Number of } \\
\text { stable } \\
\text { links } \\
\end{array}$ \\
\hline FSBEI HE "USUE" & 86 & 11 & 86 & 11 & 0 & 0 \\
\hline $\begin{array}{c}\text { UI of FSBEI HE } \\
\text { "RANEPA" }\end{array}$ & 57 & 1 & 86 & 7 & 29 & 6 \\
\hline FSAEI HE " RSVPU" & 36 & 5 & 86 & 6 & 50 & 1 \\
\hline FSAEI HE "UrFU" & 79 & 1 & 86 & 12 & 7 & 11 \\
\hline $\begin{array}{l}\text { Yekaterinburg Institute of } \\
\text { Physical Culture, branch of } \\
\text { the FSBEI HE "USUFPC" }\end{array}$ & 79 & 3 & 86 & 10 & 7 & 7 \\
\hline $\begin{array}{l}\text { FSBEI HE "U I of SFS of } \\
\text { the Ministry of Emergency } \\
\text { Situations" }\end{array}$ & 86 & 3 & 86 & 10 & 0 & 7 \\
\hline FSBEI HE "USMU" & 64 & 4 & 86 & 8 & 22 & 4 \\
\hline FSBEI HE "USPU" & 79 & 1 & 86 & 10 & 7 & 9 \\
\hline FSBEI HE "USLU" & 71 & 2 & 79 & 5 & 8 & 3 \\
\hline FSBEI HE "USAU" & 57 & 2 & 79 & 8 & 22 & 6 \\
\hline FSBEI HE "USUAA" & 79 & 3 & 64 & 7 & -15 & 4 \\
\hline FSBEI HE "USMU" & 79 & 2 & 86 & 8 & 7 & 6 \\
\hline FSBEI HE "USFU" & 64 & 2 & 86 & 8 & 22 & 6 \\
\hline FSBEI HE "USUR" & 57 & 2 & 86 & 4 & 29 & 2 \\
\hline
\end{tabular}

within the framework of the proposed approach made it possible to determine a new architecture of network interaction within the framework of the physical culture and sports activities of the universities of the Sverdlovsk region, which makes it possible to increase the intensity of participation of universities in various events, as well as significantly expand the coverage of participants and optimize the expenditure of necessary resources. The use of the developed and tested conceptual model of strategic network management of physical culture and sports activities of the university allows to implement the provisions and methodology of both network theory and resource and relational approaches in strategic management.

The results obtained indicate a significant increase in indicators characterizing strategic network interaction both from the point of view of effectiveness: an increase in the number of persons participating in events (projects) of physical culture and sports activity, and from the point of view of indicators characterizing the architecture of the network: network coverage and the number of stable links.

\section{AUTHORS' CONTRIBUTIONS}

The title "AUTHORS' CONTRIBUTIONS" should be in all caps.

\section{ACKNOWLEDGMENTS}

The title "ACKNOWLEDGMENTS" should be in all caps and should be placed above the references. The references should be consistent within the article and follow the same style. List all the references with full details.

\section{REFERENCES}

[1] Aarikka-Stenroos How to manage innovation processes in extensive networks: A longitudinal study Industrial Marketing Management. 67 (2017).

[2] Yu. D. Yakubov Criteria of the effectiveness of regional physical culture and sports policy Vlast. 4 (2014).

[3] E. V. Popov Networks. AMB Publishing House, 2016.

[4] D. S. Mironov Transaction costs as a criterion for the effectiveness of network interaction Vestnik of the Moscow Institute of Humanities and Economics. 4 (2018).

[5] Yu. F. Popova Capital of inter-firm relations: concept and measurement methodology Manager. 4 (2017).

[6] I. V. Manzheley, S. N. Chernyakova Physical culture competence of bachelors: content and conditions for the formation The Bulletin of the Tula 
State University. Physical education. Sport. 2 (2014).

[7] P. Ryskin, M. Kocheryan, E. Davydova Selfidentification features of professional athletes in modern Russia Journal of Physical Education and Sport. 19 (2019).

[8] A. E. Plakhin, M. A. Kocherian, T. V. Volovik Research the projects characteristics in the sphere of universities' physical education and sports activities Revista Inclusiones. 7 (2020).

[9] A. M. Starostenko, K. V. Starostenko Management of physical culture and sports in the Oryol region: state and ways of improvement Central Russian Bulletin of Social Sciences. 4 (2012). 